\title{
Analytical strategies to study the formation and drug delivery capabilities of ferritin encapsulated cisplatin in sensitive and resistant cell models.
}

D. Turiel-Fernández, E. Blanco-González, M. Corte-Rodríguez, J. Bettmer and M. Montes-Bayón*.

Department of Physical and Analytical Chemistry. Faculty of Chemistry and Instituto de Investigación Sanitaria del Principado de Asturias (ISPA). University of Oviedo.

C/ Julian Clavería 8. 33006 Oviedo. SPAIN.

*Corresponding author:

E-mail address: montesmaria@uniovi.es. Phone number: +(34)-985103478

\begin{abstract}
One of the limitations in the use of cisplatin is its low penetration into cells. In addition, some cells develop the so called resistance, a multifactorial event that decreases significantly the intracellular cisplatin concentration. To circumvent these limitations, recent studies are focused on the use of nanocarriers that permit, among others, to achieve higher drug uptake. In this work, ferritin is evaluated as nanostructured cisplatin-delivery system in cell models of ovarian cancer. One of the key aspects is the characterization encapsulated product and for this aim a battery of analytical techniques, including Size Exclusion Chromatography (SEC) coupled to UV-detection and to inductively coupled plasma mass spectrometry (ICP-MS) together with transmission electron microscopy (TEM) is conducted. Higher level of incorporation occurs when using initial concentrations of the Fe-containing form of the protein at $10 \mathrm{mg} / \mathrm{mL}$ and 1
\end{abstract}


$\mathrm{mg} / \mathrm{mL}$ cisplatin solution. The incorporation of the free and encapsulated cisplatin is addressed in A2780 and A2780CIS, sensitive and cisplatin resistant cell lines respectively, showing a significantly higher uptake of the encapsulated form. These values ranged from 5 to 9-fold in the sensitive line and 2-4 in the resistant model, being always more pronounced at the lower doses. Functionality of the drug after encapsulation is addressed by monitoring the presence of Pt in DNA and normalizing DNA concentration through simultaneous $\mathrm{P}$ and $\mathrm{Pt}$ measurements by ICP-MS. Time elapsed between exposure and Pt detection in DNA proved to be critical in the encapsulated model, showing the slower drug-release mechanism from the ferritin nanocage that could be advantageously used for a controlled therapy.

Key-words: encapsulation, cisplatin, ferritin, ICP-MS, DNA 


\section{Introduction}

Chemotherapy conventionally involves the use of synthetic molecules and natural products that in general are low molecular weight compounds. Such agents inherently suffer from sub-optimal utilization due to rapid clearance and short blood circulation half-lives [1, 2]. In addition, some of the administrated chemotherapeutic agents undergo unspecific interactions with healthy tissues during the transmission and distribution of the drugs in the body, which results in significantly high toxic effects [3] . Therefore, controlled drug delivery systems offer a potential way to overcome the challenges with the administration and release of anticancer drugs. In the particular case of cisplatin (cis-diamminedichloroplatinum [II]), one of the intravenously administrable $\mathrm{Pt}(\mathrm{II})$ complexes approved for worldwide clinical practice, toxicity effects as well as developed or acquired drug resistance limit the maximum dose that can be applied for a positive outcome $[4,5]$. Thus, several alternatives to reduce the general toxicity and to improve therapeutic efficacy using drug nanocarriers have been proposed over the years [6].

Among them, liposomes have been proposed as an efficient mean to reduce systemic cisplatin toxicity by encapsulation of cisplatin within a lipidic vessel that protects the drug from degradation in the biological environment [7]. The main advantage of these systems is that while most clinically used anticancer drugs rapidly pass through the membranes of both normal and cancerous tissues, the drugs coupled to liposomes, lipid particles and micelles selectively accumulate in tumors [8]. In this regard, Lipoplatin (Regulon, Inc.) is one of the most promising liposomal platinum drug formulations under clinical investigation containing about $9 \%$ of cisplatin and $91 \%$ lipids 
resulting in a 1:10 drug to lipid ratio [9]. Preclinical studies of Lipoplatin in mice, rats and in severe combined immunodeficient mice reported that it has lower side effects, and notably less toxicity compared to cisplatin [10]. Besides Lipoplatin, a particular high potential is foreseen in nanoscale formulations that permit cellular targeting and prolonged circulation times while maintaining improving drug efficacy and reducing unwanted side effects [11].

An interesting alternative to liposomes is the encapsulation of cisplatin within ferritin nanocages that has been explored in some recent studies [12, 13]. Human ferritin, the primary iron storage protein, contains an internal nanocage of about $8 \mathrm{~nm}$ of internal diameter partially loaded by Fe atoms. These nanocages can be used for incorporation of other compounds like cisplatin providing important advantages with respect to other systems, particularly for human applications in vivo [14]. The most remarkable one is that human ferritin is present in both, cells and blood under physiological conditions. Being a natural self-constituent of biological systems it is less likely to induce strong cell immune responses [15]. It is a stable protein that is soluble in the bloodstream and amenable to both, genetic and chemical functionalization [16]. Several groups have reported that ferritins are effective templates for loading, in their internal cavity, imaging agents for magnetic resonance imaging (MRI), positron emission tomography (PET), and metal based drugs such as cisplatin [17].

Regarding the chemical structure, ferritin can be present as apoferritin (hollow form) or holoferritin (containing Fe atoms up to 2500 per molecule of ferritin). It is a protein complex of approximately $450 \mathrm{kDa}$ consisting of 24 polypeptide subunits, which assemble into a hollow sphere, and containing small channels located at the subunit 
junctions required for the release of iron and transport of other metal ions and small molecules (e.g. cisplatin). In 2007, it was first shown that cisplatin could be encapsulated in the cavity of apoferritin resulting in a drug-loaded protein that shows the potential to exert appreciable cytotoxic effects on tumor cells [12]. It has been shown that Pt uptake in the encapsulated form is higher than that of the free drug in some cell models suggesting that the encapsulated drug is internalized more easily than the drug alone.

However, very little work has been conducted to evaluate the efficacy of the encapsulation of cisplatin as well as drug functionality after cellular internalization (e.g. DNA interaction capabilities, cytotoxicity, etc.). Since this is a complex metallomic problem, a plethora of analytical strategies have to be optimized and complementarily applied. Therefore, this work is aimed first, to study the encapsulation conditions by means of chromatographic strategies (SEC) coupled on-line with UV and inductively coupled plasma mass spectrometry (ICP-MS) as Pt selective detector. The complementary information of the UV and ICP-MS data will allow to quantify the exact concentration of the encapsulated drug as well as the detection of any existing traces of the "free" form. The combination of ICP-MS and TEM (using also X-Ray elemental analysis) will permit to address the shape and morphology of the synthetic product. Second, the cellular uptake of the encapsulated cisplatin in two cell models (A2780 and A2780cis), sensitive and resistant to cisplatin, respectively, is addressed in comparison to the free drug. Furthermore, since cisplatin cytotoxic effects are based on cisplatinDNA adducts formation, the specific interaction from the free and the encapsulated drug with the DNA of the exposed cells will be also determined using ICP-MS as P and Pt detector using a previously optimized strategy. 


\section{Materials and methods}

\section{Reagents and solutions}

All working solutions were prepared using $18 \mathrm{M} \Omega \mathrm{cm}$ de-ionized water obtained from a PURELAB flex 3 (ELGA VEOLIA, Lane End, United Kingdom). The platinum ICP-MS standard was purchased form Merck (Darmstadt, Germany) and the ferritin standard from equine spleen and cisplatin (cis-diamminedichloroplatinum(II)) standard were purchased from Sigma-Aldrich (St. Louis, MO, USA). For the encapsulation, hydrochloric acid was obtained from Merck Millipore and sodium hydroxide from Fisher Scientific. DNA from salmon sperm was purchased from Sigma-Aldrich. SEC separation was done using a mobile phase containing $50 \mathrm{mmol} \mathrm{L}^{-1}$ ammonium acetate (Merck Millipore), $\mathrm{pH}=7.4$. Nitric acid (65\%, suprapur quality) and hydrogen peroxide (30\%) were purchased from Merck.

\section{Instrumentation}

An iCAP TQ ICP-MS (Thermo Fisher Scientific, Bremen, Germany) was used for this study using the single quadrupole (SQ) mode. For the chromatographic separation of the encapsulated cisplatin, size exclusion chromatography (SEC) was used. The mobile phase was pumped using an Agilent $1260 \mathrm{HPLC}$ instrument (Agilent Technologies, Tokyo, Japan) at a flow of $0.7 \mathrm{~mL} \mathrm{~min} \mathrm{~m}^{-1}$ injecting $20 \mu \mathrm{L}$. The size exclusion chromatographic column was a Superdex 200 10/300 GL (300 mm x 10 mm i.d., GE Healthcare BioSciences, Sweden) having a fractionation range from 10 to $600 \mathrm{kDa}$. Vis/UV absorbance was registered at $280 \mathrm{~nm}$ using a Diode Array Detector (DAD) (Agilent Technologies). 
For the flow injection set-up used for the analysis of total $\mathrm{Pt}$, the carrier $\left(\mathrm{HNO}_{3}\right.$ $0.1 \%)$ was pumped using a peristaltic pump $\left(0.5 \mathrm{~mL} \mathrm{~min}^{-1}\right)$ and the sample was injected using a dual mode injection valve from Rheodyne, model 9725 (Cotati, California, USA), fitted with a $20 \mu \mathrm{L}$ injection loop. HR-TEM images were obtained in a JEOL-JEM $2100 \mathrm{~F}$ (Tokyo, Japan) transmission electron microscope with an operation voltage of $200 \mathrm{kV}$ to image encapsulated solutions on $\mathrm{Cu}$ grids. The instrument also allows to obtain elemental information of the sample by energy-dispersive X-ray spectroscopy (EDX).

\section{Cell culture and lysis}

The human ovarian carcinoma cell line A2780 was a kind gift from Dr. J.M. Pérez Freije (Department of Biochemistry and Molecular Biology, University of Oviedo, Spain). The Biotechnological and Biomedical Assay Unit from the Scientific and Technical Services (SCTs) of the University of Oviedo, authenticated this cell line using the AmpFLSTR ${ }^{\circledR}$ Identifier ${ }^{\circledR}$ Plus-PCR Amplification Kit (Thermo Scientific). The A2780cis cell line was purchased form the European Collection of cell cultures through Sigma-Aldrich. Cells were cultured at $37^{\circ} \mathrm{C}$ in a $5 \% \mathrm{CO}_{2}$ atmosphere, using RPMI 1640 medium (Invitrogen, Fisher Scientific, Madrid, Spain) containing $5 \mathrm{mg} \mathrm{L}^{-1}$ of Plasmocin (InvivoGen, San Diego, USA). The medium was supplemented with $10 \%$ fetal bovine serum (Invitrogen, Carlsbad, USA).

Cells were cultured in six well plates $\left(2 \times 10^{6}\right.$ cells approximately where collected). In the uptake experiments, cells were exposed to free and ferritin encapsulated cisplatin, respectively, at 0,1 and $3 \mu \mathrm{mol} \mathrm{L}^{-1}$ concentrations for 24 hours at $37^{\circ} \mathrm{C}$, afterwards they were washed with PBS, collected by trypsinization and pelleted by centrifugation. To evaluate the Pt in the DNA, cells were exposed to free and 
encapsulated cisplatin, respectively, at $2 \mu \mathrm{mol} \mathrm{L}^{-1}$, for 24 hours. In addition, in a parallel experiment, other cells were left to rest for $24 \mathrm{~h}$ after cisplatin (free or encapsulated) exposition in clean media before collection. For evaluation of the Pt uptake in cells, the cells pellet were first lyophilized (by freeze-drying) and then weighed in a high precision balance (New ClassicMS105DU, Mettler Toledo, Spain) to obtain cells dry weight. Afterwards, $500 \mu \mathrm{L}$ of $65 \% \mathrm{HNO}_{3}$ were added to the freeze dried pellet and then heated at $70^{\circ} \mathrm{C}$ for $1 \mathrm{~h}$. After this time, $500 \mu \mathrm{L}$ of $30 \% \mathrm{H}_{2} \mathrm{O}_{2}$ were added to the mixture and the mixture was heated at $70^{\circ} \mathrm{C}$ for $4 \mathrm{~h}$ more. The final solution was diluted to determine total Pt concentration by ICP-MS according to previously stablished methodologies [18]. All the measurements were taken by triplicate.

\section{DNA extraction}

Genomic DNA from cells was extracted and purified with a silica-based column DNA purification kit PureLink ${ }^{T M}$ Genomic DNA Mini Kit (Invitrogen). Manufacturer's instructions were followed including the incorporation of RNAse to have a RNA-free genomic DNA. The extracted DNA was eluted in $100 \mu \mathrm{L}$ of ultrapure water. The DNA from the cells exposed to free and encapsulated cisplatin for $24 \mathrm{~h}$ was directly extracted after exposure. Same procedure was used for cells exposed to the drug for $24 \mathrm{~h}$ followed by $24 \mathrm{~h}$ of rest in clean media.

The concentration of DNA was determined by referring the ${ }^{31} \mathrm{P}$ signal obtained in the sample by ICP-MS to the P signal obtained after acid digestion of different DNA standards from salmon sperm DNA (Sigma) containing 2, 8, 15 and $20 \mathrm{mg} \mathrm{L}^{-1}$ DNA. Then, sample was adequately diluted for analysis by ICP-MS. This procedure has been optimized in a previous publication [18]. 


\section{Cytotoxicity assay}

The toxicity of the different drugs (free and encapsulated cisplatin) was evaluated using a cell counting Kit-8 (CCK-8) assay kit from Sigma-Aldrich. For this aim, cells were seeded in 96-well plates for $24 \mathrm{~h}$ prior to being exposed to the free and encapsulated cisplatin, respectively, at concentrations ranging from 0.01 to $3 \mu \mathrm{mol} \mathrm{L} \mathrm{L}^{-1}$. After the time of the treatment $(24 \mathrm{~h})$, the CCK-8 compound was added to each well and incubated for $2 \mathrm{~h}$ at $37^{\circ} \mathrm{C}$. The absorbance was measured at $450 \mathrm{~nm}$ using a microplate reader. Additionally, in a parallel experiment, cells treated with the encapsulated and free cisplatin for $24 \mathrm{~h}$ were allowed to rest for another $24 \mathrm{~h}$ in clean media. The cytotoxicity assay was then conducted. Every treatment at each concentration was done in triplicate. Cell viability was expressed as a percentage of that of the control (untreated) cells. For each concentration of drug, cell viability differences between cells treated with free cisplatin and cells treated with encapsulated cisplatin were evaluated using two-tailed Student's $t$ test, and $P$ values of less than 0.05 were considered to be statistically significant.

The same experiment was performed using only ferritin to address the possible effect of increasing protein concentrations. Results are shown in the Supplementary material (Figure S1).

\section{Encapsulation procedure}

For the general encapsulation procedure, $1 \mathrm{mg}$ of cisplatin was dissolved in $500 \mu \mathrm{L}$ of ultrapure water and added to a $20 \mathrm{mg} \mathrm{mL}^{-1}$ solution of ferritin prepared in $0.9 \% \mathrm{NaCl}$ to achieve a final concentration of $1 \mathrm{mg} \mathrm{mL}^{-1}$ cisplatin and $10 \mathrm{mg} \cdot \mathrm{mL}^{-1}$ ferritin. 
Cisplatin encapsulation followed the previously published protocol [12]. Briefly, once mixed the ferritin and the cisplatin solutions, the $\mathrm{pH}$ was adjusted to 2.2 using $\mathrm{HCl}$ $0.5 \mathrm{M}$ and then incubated at room temperature for $15 \mathrm{~min}$. After this time, $\mathrm{pH}$ was turned back to $\mathrm{pH} 7.5$ adding $\mathrm{NaOH} 0.5 \mathrm{M}$. The resulting solution was stirred $1 \mathrm{~h}$ at room temperature, ultrafiltrated using a $100 \mathrm{kDa}$ Amicon Ultra-0.5mL filter (Millipore, Bedford, MA, USA) and washed 3 times with $\mathrm{NaCl} 0.9 \%$ to remove unbound cisplatin. Cisplatin encapsulated inside the ferritin was stored at $-20^{\circ} \mathrm{C}$.

Encapsulation results were checked using size exclusion chromatography (SEC) coupled with ICP-MS and UV-VIS detection.

\section{Results and discussion}

\section{Analytical strategies to study the encapsulation conditions}

The encapsulation of cisplatin into ferritin nanocages is based on the unfolding of the protein subunits followed by the refolding in the presence of the drug. The first step of dissembling ferritin in the corresponding subunits was attempted by increasing the $\mathrm{pH}$ to $\mathrm{pH}=13$ (using $\mathrm{NaOH}$ ) or lowering it to $\mathrm{pH}=2$ (using $\mathrm{HCl}$ ). In both cases, the $\mathrm{pH}$ values were maintained for about $15 \mathrm{~min}$ and afterwards, adjusted stepwise back to 7.4. Evaluation of the entrapment of cisplatin within the ferritin nanocage was conducted by size exclusion chromatography coupled on-line to ICP-MS that allowed Pt monitoring and permitted to discriminate the free from the encapsulated cisplatin. Figure 1 corresponds to the SEC-ICP-MS chromatogram of ${ }^{195} \mathrm{Pt}$ using basic (Fig. 1A) and acid (Fig. 1B) conditions for ferritin unfolding. As can be observed, the treatment using basic media shows most Pt peaks in the low molecular weight region of the separation range, 
probably ascribed to free cisplatin and its different hydrolysis products but no signal seems to be detected at the time of the encapsulated products (15 min). Meanwhile, the acid treatment revealed a prevalent peak at about 15 min which corresponds to the retention time of the ferritin standard when monitoring Fe (see supplementary material). In addition, the inset of Fig. 1B shows the SEC-UV $(280 \mathrm{~nm})$ profile which reveals a single peak also at $15 \mathrm{~min}$ which corresponds to the folded ferritin. Out of these experiments it can be concluded that although drastic $\mathrm{pH}$ values can be used for ferritin dissembling, the acid media is preferable for protein unfolding and further entrapment of the drug inside.

For further characterization of the encapsulated product, HR-TEM was used. The pictures obtained are shown in Figure 2A where a homogeneous dispersion of nanostructures can be observed. The form of the particle is spherical with a mean sizes of 7-8 $\mathrm{nm}$ and relatively low dispersion in terms of particle size. If this picture is compared to previously obtained pictures of holoferritin [19], they are almost undistinguishable confirming the correct reassembling of the protein after the encapsulation procedure. Recent X-ray studies reveal His132 as the main binding site for the drug and the absence of cisplatin on the ferritin surface [20] when using a similar incorporation protocol. Therefore, the encapsulated product seems to be undistinguishable from the original ferritin except for the presence of cisplatin inside. This seems to be critical to obtain an adequate recognition by the ferritin receptors known to be present in most tumor cells [21].

In addition, X-ray analysis of the elemental composition of the encapsulated material is shown in Figure 2B. The elemental composition shows the presence of Pt and 
Fe atoms in the protein cage confirming the findings obtained by SEC-ICP-MS. The presence of iron is due to the use of the Fe-containing ferritin (holoferritin) to conduct the encapsulation studies. When the same procedure was repeated with apoferritin, similar encapsulation results were obtained. Despite the positive results observed in both cases, the use of the Fe-containing ferritin provides an additional hetero-element to be monitored by ICP-MS during the encapsulation procedure together with $\mathrm{Pt}$ and further experiments were conducted using the Fe-containing form.

One main issue while encapsulating cisplatin into ferritin that has been also observed during protein manipulation (also observed in commercial ferritin standards) refers to the formation of protein oligomers. This is probably ascribed to a redox process that yields the formation of di-thiol bridges among protein monomers (see Figure S3 in the supplementary material). In this case, this observation does not seem to affect the cisplatin in the encapsulation process since the oligomers are also observed after encapsulation. Working under the same conditions, the formation of the oligomers seems to be random and it is observed with higher or lower intensity independently from the concentration of protein and/or cisplatin.

\section{Quantification of the encapsulated form of cisplatin}

To address the quantitative aspects of the encapsulation process, different experiments were conducted. First, the concentration of ferritin before and after encapsulation was obtained by SEC-UV using commercial ferritin standards to address the protein recovery after the whole procedure. The overall ferritin recovery was about $10 \pm 3 \%$ (mean $\pm S D$, $\mathrm{n}=3$ ) (using $10 \mathrm{mg} \mathrm{mL}^{-1}$ initial protein concentration) revealing important losses throughout the whole procedure. Furthermore, in order to address best encapsulating 
conditions, the concentration of ferritin was kept constant and the concentration of cisplatin was varied from 0.5 to $2 \mathrm{mg} \mathrm{mL}^{-1}$. For the quantification of the encapsulated cisplatin, a flow injection-ICP-MS calibration curve of Pt was obtained, while the protein concentration was measured using SEC-UV. The obtained results revealed a more favorable stoichiometry in the case of encapsulating $1 \mathrm{mg} \mathrm{mL}^{-1}$ cisplatin obtaining a molar ratio of about 2:1 (cisplatin:ferritin), in complete agreement with previous stoichiometries reported in the literature [12].

\section{Release of the encapsulated cisplatin from ferritin}

The release of cisplatin from the encapsulated form is expected to be $\mathrm{pH}$ dependent. Therefore, an evaluation of the effect of $\mathrm{pH}$ on the release of cisplatin from the ferritin cage was conducted by incubating the encapsulated product in different buffer solutions with $\mathrm{pH}$ values between 5.5 (obtained in the cellular endosomes) to 7.5 (physiological of blood serum). The incubations were carried out for 5,24 and 48 hours, respectively, and the reaction products were analyzed by SEC-ICP-MS in order to quantify the free and encapsulated cisplatin. As an example of the different $\mathrm{pH}$ values assayed Figure 3 shows the release of cisplatin from the ferritin cage at $\mathrm{pH} 7.5$ (grey trace) and at $\mathrm{pH} 5.5$ (blue trace). It can be seen that the ratio free/encapsulated cisplatin increases by about 4-fold and remains constant after 5 hours of incubation at pH 5.5 (blue trace). On the other hand, when the incubation is done at $\mathrm{pH} 7.5$ (grey trace) the ratio free/encapsulated cisplatin showed constant trend over $48 \mathrm{~h}$ of incubation. This finding might be an important advantage in the case of the intravenous administration of the encapsulated drug since at physiological $\mathrm{pH}(\mathrm{pH} 7.5$, Fig. 3 ) the drug is safely packed within the protein structure. Therefore, it could be transported within the blood stream with minimum interaction with other serum proteins, as reported for free cisplatin [22]. 
Once reaching the tumor cells, the ferritin is expected to be endocyted by using specific ferritin and also transferrin receptors (e.g. transferrin receptor 1) present on the cellular surface [23]. The lowering of $\mathrm{pH}$ in the endosomes to approximately $\mathrm{pH} 5.5 \mathrm{might}$ generate changes on the protein folding. In this regard, the obtained results showed that, at this $\mathrm{pH}$, the protein releases the encapsulated cisplatin almost completely $(35 \%$ remaining inside) in $24 \mathrm{~h}$. Thus, a controlled drug release within the cells is expected in the encapsulated model.

\section{Comparative cell uptake in sensitive and resistant cell models}

Once synthesized and characterized, the cellular uptake of encapsulated cisplatin was compared with that of the free drug. This study was conducted in two cell models of ovarian cancer: A2780 (sensitive to cisplatin) and A2780cis (resistant to cisplatin). Previous studies in our research group with these two cell lines revealed that the incorporation of cisplatin is about five times lower in the resistant model in comparison to the sensitive one [24]. Therefore, in order to address the effect of the drug encapsulation on the uptake, different drug concentrations $\left(0,1\right.$ and $3 \mu \mathrm{mol} \mathrm{L}^{-1}$ for $24 \mathrm{~h}$ ) in the free and encapsulated forms were incubated with the two cell models. To achieve an accurate determination of Pt in cell cultures, a previously developed procedure was conducted where the freeze-dried cell pellet was weighted and then digested under acidic conditions. Total Pt determination was obtained by FIA-ICP-MS and the obtained results can be seen in Figure 4 ( $A$ and B, for A2780 and A2780cis, respectively).

At same concentrations, the encapsulated drug showed significantly higher cellular uptake than the non-encapsulated one. However, in the case of the sensitive line, the encapsulated cisplatin yielded in a significant increase of the uptake (around 5 
to 10 times higher). Such increase occurs also in the resistant cell line although, in this case, the improvement factor went from a 2- to 4-fold increase. The observed effect in both cell models was more pronounced at lower exposure drug concentrations. Considering the high occurrence of ferritin receptors in the surface of most tumor cells it is likely that ferritin can act as a "Trojan horse" to incorporate cisplatin in a more efficiently way [25]. This could be even more important in resistant cell models, where the limited uptake of the drug is considered as one of the reasons for resistance [18].

\section{Interactions with DNA and cellular toxicity}

Once the drug uptake was addressed, the functionality of the encapsulated model needed to be evaluated. Since the main target molecule for cisplatin interaction is DNA, total Pt determination in extracted DNA from exposed cells to both, free and encapsulated cisplatin at the same concentration $\left(2 \mu \mathrm{mol} \mathrm{L}^{-1}\right)$ was conducted. Due to the similar behavior regarding interaction with DNA observed for these two cell lines (ranging 1-2\% of the intracellular Pt) [18] and the significantly lower uptake in the A2780cis, these experiments were only conducted with the sensitive model (A2780). Two sets of experiments were prepared: in the first one, cells were treated for $24 \mathrm{~h}$ and harvested right after exposure; in the second experiment, cells were also treated for 24 $\mathrm{h}$ but were left to rest in clean media for $24 \mathrm{~h}$ before harvesting. The obtained results are plotted in Figure 5 and reported as ng Pt/mg DNA obtained by measuring $\mathrm{P}$ and $\mathrm{Pt}$ in the DNA by ICP-MS and correlating $\mathrm{P}$ concentration to DNA concentration as previously conducted [18]. As can be seen, highest Pt concentration in DNA is observed when cells are exposed to the free drug and harvested immediately. However, after 24 $\mathrm{h}$ of cell rest, all the Pt-DNA adducts have been almost eliminated and the level of Pt in 
the DNA is close to the value of the control (untreated) cells. Such finding agrees with previous experiments conducted in our group where DNA-cisplatin adducts have shown to be totally repaired after 24 hours [26]. The encapsulated drug, on the other hand, shows a different behavior. In this case, the amount of adducted Pt to DNA after $24 \mathrm{~h}$ is significantly lower than that for the free drug but the situation reverses after $24 \mathrm{~h}$ of cell rest. The encapsulated drug, on the other hand, requires some time for complete release from the protein nanocage and activation to finally interact with DNA. In this regard, highest levels of Pt interacted with DNA are found once cells are left to stand in clean media for another $24 \mathrm{~h}$. It cannot be discarded that these levels are also maintained for longer times. Thus, the encapsulated cisplatin fulfills also the desired property of achieving higher clearance time than the free compound, as desired property of the nanoencapsulated structures.

Lastly, the effect in terms of cellular toxicity using the CCK-8 assay of the encapsulated model versus the free drug is illustrated in Fig. 6 and can be correlated with the measurement of Pt in DNA shown in Fig. 5 . The cells viability was addressed after $24 \mathrm{~h}$ exposure (Figure $6 \mathrm{~A}$ ) and after $24 \mathrm{~h}$ exposure $+24 \mathrm{~h}$ recovery in drug-free media (Figure 6B). The toxic effect of adding ferritin (used as vehicle for the drug) was also addressed with negligible results (supplementary material). As can be observed in Fig. $6 \mathrm{~A}$, after $24 \mathrm{~h}$ exposure and direct measurement, the cell viability decreases in the same extend upon increasing drug concentration (both forms, free and encapsulated). Final cell viability of about $50 \%$ was obtained at concentration of about $3 \mu \mathrm{mol} \mathrm{L}^{-1}$ of both the free and the encapsulated cisplatin. 
However, the results are different when cells are left to rest for another $24 \mathrm{~h}$ in clean media before measuring cell viability. In that case, there are differences in cell viability on the treatments with either free or encapsulated cisplatin at $1.5 \mu \mathrm{mol} \cdot \mathrm{L}^{-1}$ concentration being the encapsulated form more toxic to cells than the free form $(75 \%$ cell viability vs $95 \%$ ) with statistically significant differences at the $10 \%$ confidence level $(P<0.1)$. This effect is more pronounced at $3 \mu \mathrm{mol} \cdot \mathrm{L}^{-1}$, where the free compound provides a descent to cell viability down to $75 \%$ while the encapsulated form goes down to $35 \%$ viability. In this case, the observed decrease in cell viability is statistically significant at the $5 \%$ confidence level $(P<0.05)$.

Such result confirms that together with the longer residence time, the encapsulated drug is still active against tumor cells even after $48 \mathrm{~h}$ of administration. Therefore, lower drug concentrations could be given to obtain similar clinical outcome due to the slower elimination of the compounds by adduct repairing

\section{Conclusions}

The encapsulation of cisplatin into ferritin nanocages can be accomplished using the strategy here proposed. The characterization of the synthetic product by means of SECICP-MS and TEM reveal an effective incorporation of the drug within the protein structure and the correct reassembling of the subunits after decreasing and further increasing the $\mathrm{pH}$. The encapsulated form seems to be stable under physiological $\mathrm{pH}$ conditions and starts to release the drug at $\mathrm{pH} 5.5$, corresponding to the $\mathrm{pH}$ encountered in cellular endosomes. The encapsulated form has shown to be efficiently taken up by cells, in particular A2780 (sensitive to cisplatin), in comparison to the free form. This effect can be also observed but in a lower extent in cisplatin resistant cell models. Such 
finding reveals the positive effect of ferritin as "Trojan horse" to increase the cellular incorporation of cisplatin in cells. The accumulated cisplatin seems to be highly efficient to undergo further interaction with DNA, the target molecule. The formation of cisplatin-DNA adducts seems to be even more efficient after $48 \mathrm{~h}$ in the encapsulated model, providing higher cellular toxicity. Thus, encapsulated cisplatin into ferritin nanocages seems to provide a biocompatible mean of increasing cisplatin efficacy in cell cultures by avoiding drug inactivation, increasing residence time and higher cellular penetration.

\section{Acknowledgements}

The authors want to acknowledge the Ministry of Economy and Competitiveness for the financial support through the project MINECO-17-CTQ2016-80069-C2-1-R and MCIU-19RTI2018-094605-B-100. Also, to the Asturias government for the regional funding throw the Science, Technology and Innovation Plan (PCTI) co-financed by FEDER funds (GRUPIN-18 IDI/2018/000242). D. Turiel-Fernández acknowledges also his grant from the Spanish Ministry of Education and Science referenced FPU15/02415. The instrumental support (iCAP TQ ICP-MS) of Thermo Fisher Scientific and the assistance from A. Fernandez Asensio and M. Garcia Ocaña from the Biotechnology and Biomedical Analysis Unit at University of Oviedo, with cells handling are also acknowledged.

\section{Compliance with Ethical Standards}

The authors have no conflicts of interest to declare. 


\section{References}

1. Vermorken JB, van der Vijgh WJ, Klein I, Hart AA, Gall HE PH. Pharmacokinetics of free and total platinum species after short-term infusion of cisplatin. Cancer Treat Rep 1984; 68:505-513

2. Urien S, Lokiec F. Population pharmacokinetics of total and unbound plasma cisplatin in adult patients. Br J Clin Pharmacol 2004;57:756-763 . https://doi.org/10.1111/j.13652125.2004.02082.x

3. Karasawa T, Steyger PS. An integrated view of cisplatin-induced nephrotoxicity and ototoxicity. Toxicol Lett 2015;237:219-227

4. Galluzzi L, Vitale I, Michels J, Brenner C, Szabadkai G, Harel-Bellan A, Castedo M, Kroemer G. Systems biology of cisplatin resistance: Past, present and future. Cell Death Dis 2014; 5

5. Zisowsky J, Koegel S, Leyers S, Devarakonda K, Kassack MU, Osmak M, Jaehde U. Relevance of drug uptake and efflux for cisplatin sensitivity of tumor cells. Biochem Pharmacol 2007;73:298-307 . https://doi.org/10.1016/j.bcp.2006.10.003

6. Oberoi HS, Nukolova N V., Kabanov A V., Bronich TK. Nanocarriers for delivery of platinum anticancer drugs. Adv Drug Deliv Rev 2013; 65:1667-1685

7. Stathopoulos GP, Boulikas T. Lipoplatin Formulation Review Article. J Drug Deliv 2011; 2012:1-10 . https://doi.org/10.1155/2012/581363

8. Sawant RR, Torchilin VP. Liposomes as'smart' pharmaceutical nanocarriers. Soft Matter 2010; 6:4026-4044 . https://doi.org/10.1039/b923535n

9. T. B. Low toxicity and anticancer activity of a novel liposomal cisplatin (Lipoplatin) in mouse xenografts. Oncol Rep 2004; 12:3-12

10. Leite EA, Lana ÂMQ, Carvalho ÁD, Coelho LGV, De Oliveira MC. Acute toxicity study of cisplatin loaded long-circulating and $\mathrm{pH}$-sensitive liposomes administered in mice. J Biomed Nanotechnol 2012; 8:229-239 . https://doi.org/10.1166/jbn.2012.1388

11. Parhizkar M, Reardon PJT, Knowles JC, Browning RJ, Stride E, Barbara PR, Harker AH, Edirisinghe M. Electrohydrodynamic encapsulation of cisplatin in poly (lactic-co-glycolic acid) nanoparticles for controlled drug delivery. Nanomedicine Nanotechnology, Biol Med 2016; 12:1919-1929 . https://doi.org/10.1016/j.nano.2016.05.005

12. Yang Z, Wang X, Diao H, Zhang J, Li H, Sun H, Guo Z. Encapsulation of platinum anticancer drugs by apoferritin. Chem Commun 2007; 3453-3455 . https://doi.org/10.1039/b705326f

13. Falvo E, Tremante E, Fraioli R, Leonetti C, Zamparelli C, Boffi A, Morea V, Ceci P, Giacomini P. Antibody-drug conjugates: Targeting melanoma with cisplatin 
encapsulated in protein-cage nanoparticles based on human ferritin. Nanoscale 2013; 5:12278-12285 . https://doi.org/10.1039/c3nr04268e

14. Ji XT, Huang L, Huang HQ. Construction of nanometer cisplatin core-ferritin (NCC-F) and proteomic analysis of gastric cancer cell apoptosis induced with cisplatin released from the NCC-F. J Proteomics 2012; 75:3145-3157.

https://doi.org/10.1016/j.jprot.2012.03.013

15. Bode SA, Minten IJ, Nolte RJM, Cornelissen JJLM. Reactions inside nanoscale protein cages. Nanoscale 2011; 3:2376-2389 . https://doi.org/10.1039/c0nr01013h

16. He D, Marles-Wright J. Ferritin family proteins and their use in bionanotechnology. $\mathrm{N}$. Biotechnol. 2015; 32:651-657

17. Ghosh S, Mohapatra S, Thomas A, Bhunia D, Saha A, Das G, Jana B, Ghosh S. Apoferritin Nanocage Delivers Combination of Microtubule and Nucleus Targeting Anticancer Drugs. ACS Appl Mater Interfaces 2016; 8:30824-30832 . https://doi.org/10.1021/acsami.6b11798

18. Corte-Rodríguez M, Espina M, Sierra LM, Blanco E, Ames T, Montes-Bayón M, SanzMedel A. Quantitative evaluation of cellular uptake, DNA incorporation and adduct formation in cisplatin sensitive and resistant cell lines: Comparison of different Ptcontaining drugs. Biochem Pharmacol 2015; 98:69-77 . https://doi.org/10.1016/j.bcp.2015.08.112

19. Konz T, Montes-Bayón M, Sanz-Medel A. Incorporation of 57Fe-isotopically enriched in apoferritin: Formation and characterization of isotopically enriched Fe nanoparticles for metabolic studies. Analyst 2014; 139:5451-5459 . https://doi.org/10.1039/c4an01187b

20. Pontillo N, Pane F, Messori L, Amoresano A, Merlino A. Cisplatin encapsulation within a ferritin nanocage: A high-resolution crystallographic study. Chem Commun 2016; 52:4136-4139 . https://doi.org/10.1039/c5cc10365g

21. Li JY, Paragas N, Ned RM, Qiu A, Viltard M, Leete T, Drexler IR, Chen X, Sanna-Cherchi S, Mohammed F, Williams D, Lin CS, Schmidt-Ott KM, Andrews NC, Barasch J. Scara5 Is a Ferritin Receptor Mediating Non-Transferrin Iron Delivery. Dev Cell 2009; 16:35-46 . https://doi.org/10.1016/j.devcel.2008.12.002

22. Esteban-Fernández D. Atomic (HPLC-ICP-MS) and molecular mass spectrometry (ESI-QTOF) to study cis-platin interactions with serum proteins. J Anal At Spectrom 2009; 23:378-384 . https://doi.org/10.1039/B711922D

23. Li L, Fang CJ, Ryan JC, Niemi EC, Lebrón JA, Björkman PJ, Arase H, Torti FM, Torti S V., Nakamura MC, Seaman WE. Binding and uptake of $\mathrm{H}$-ferritin are mediated by human transferrin receptor-1. Proc Natl Acad Sci 2010; 107:3505-3510 . https://doi.org/10.1073/pnas.0913192107

24. Corte Rodríguez M, Álvarez-Fernández García R, Blanco E, Bettmer J, Montes-Bayón M. Quantitative Evaluation of Cisplatin Uptake in Sensitive and Resistant Individual Cells by 
Single-Cell ICP-MS (SC-ICP-MS). Anal Chem 2017; 89:11491-11497 .

https://doi.org/10.1021/acs.analchem.7b02746

25. Geninatti Crich S, Cadenazzi M, Lanzardo S, Conti L, Ruiu R, Alberti D, Cavallo F, Cutrin

JC, Aime S. Targeting ferritin receptors for the selective delivery of imaging and therapeutic agents to breast cancer cells. Nanoscale 2015; 7:6527-6533 .

https://doi.org/10.1039/c5nr00352k

26. Espina M, Corte-Rodríguez M, Aguado L, Montes-Bayón M, Sierra MI, Martínez-Camblor $P$, Blanco-González $E$, Sierra LM. Cisplatin resistance in cell models evaluation of metallomic and biological predictive biomarkers to address early therapy failure. Metallomics 2017; 9:564-574 . https://doi.org/10.1039/c7mt00014f 


\section{Legends of Figures}

Figure 1. Chromatogram obtained by SEC-ICP-MS monitoring ${ }^{195} \mathrm{Pt}$ of the product of the encapsulation reaction of cisplatin in ferritin nanocages by disassembling the protein subunits in: A) basic media ( $\mathrm{pH}=13)$ and $\mathrm{B})$ acid media $(\mathrm{pH}=2)$. The inset shows the profile for the same sample by SEC-UV. Retention time of ferritin standard approximately $15.5 \mathrm{~min}$ (see supplementary electronic material).

Figure 2. Transmission electron microscopy (TEM) results showing the spherical inner core of ferritin after reassembling with a mean size of $8 \mathrm{~nm}(A)$ and the elemental composition (B) including Fe and Pt.

Figure 3. Release of cisplatin from the ferritin nanocage with time upon incubation in different buffered media by measuring the ratio free to encapsulated Pt by SEC-ICP-MS. Grey trace $(\mathrm{pH}=7.5)$ and blue trace $(\mathrm{pH}=5.5)$.

Figure 4. Cellular uptake of free and encapsulated cisplatin in different cell models: A) A2780, sensitive to cisplatin and B) A2780cis, resistant to cisplatin. Red bars correspond to control samples, blue bars correspond to $1 \mu \mathrm{mol} \mathrm{L}^{-1}$ of free cisplatin (solid bars) and encapsulated (dashed bars), and grey bars correspond to $3 \mu \mathrm{mol} \mathrm{L^{-1 }}$ of free cisplatin (solid bars) and encapsulated (dashed bars). Data are expressed as mean (columns) \pm SD (bars) ( $n=3)$

Figure 5. Platinum in DNA of A2780 cell line measured after exposure to $2 \mu \mathrm{mol} \mathrm{L}^{-1}$ of free (dashed bars) or encapsulated (solid bars) cisplatin. The blue results correspond to measurements taken right after exposure and the grey ones to cells that rested $24 \mathrm{~h}$ after exposure in clean media. Data are expressed as mean (columns) $\pm S D$ (bars) $(n=3)$

Figure 6. Cell viability experiments after $24 \mathrm{~h}(\mathrm{~A})$ and $24 \mathrm{~h}+24 \mathrm{~h}$ of rest (B) in A2780 cells exposed to different concentrations of free (grey bars) and encapsulated (blue bars) cisplatinData are expressed as mean (columns) $\pm S D$ (bars) $(n=3) . *{ }^{* *}$ indicates $\mathrm{P}<0.05$ and $\mathrm{P}<0.1$, respectively, with respect to cells treated with free cisplatin. 
A)
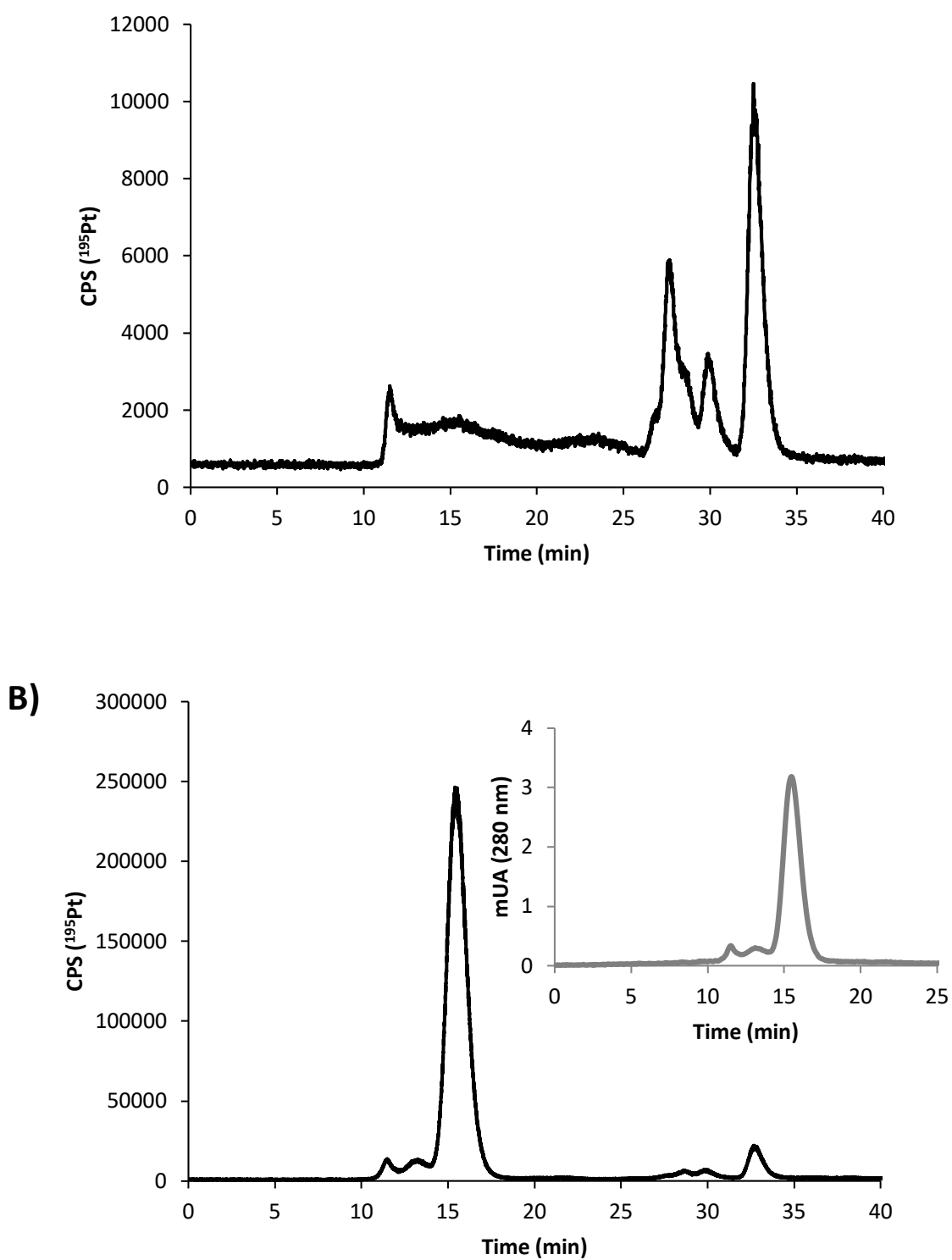

Figure 1 
A)

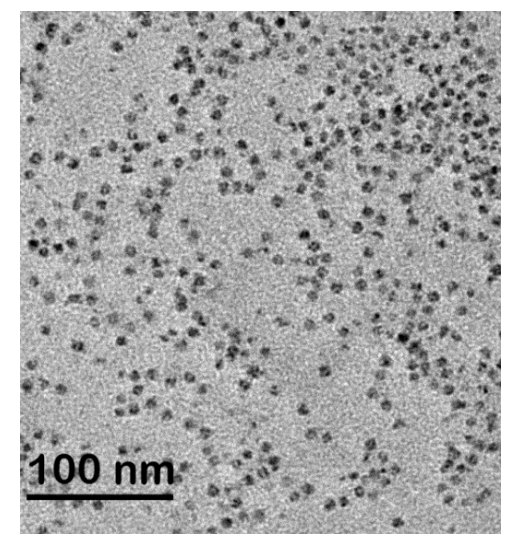

B)

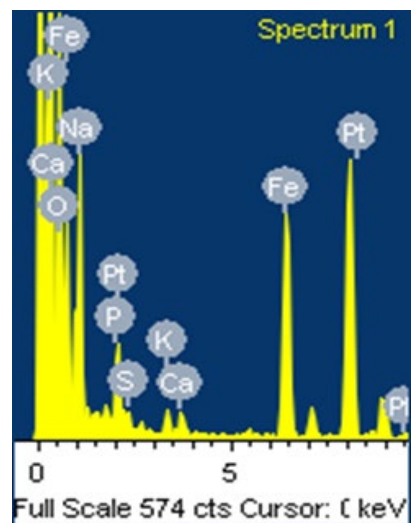

Figure 2 


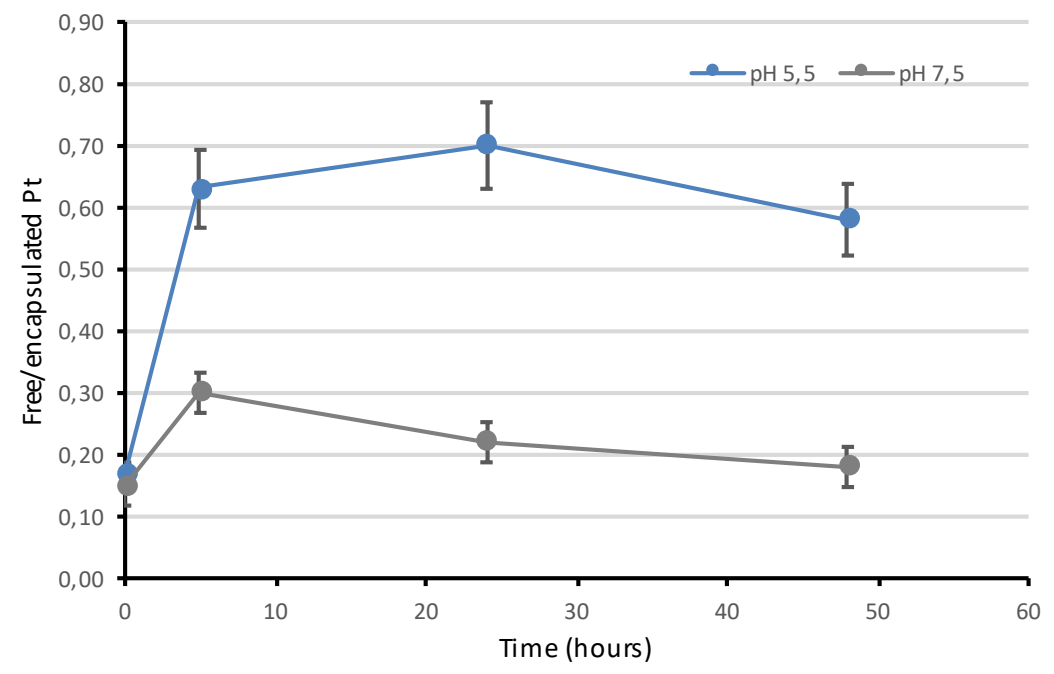

Figure 3 
A)

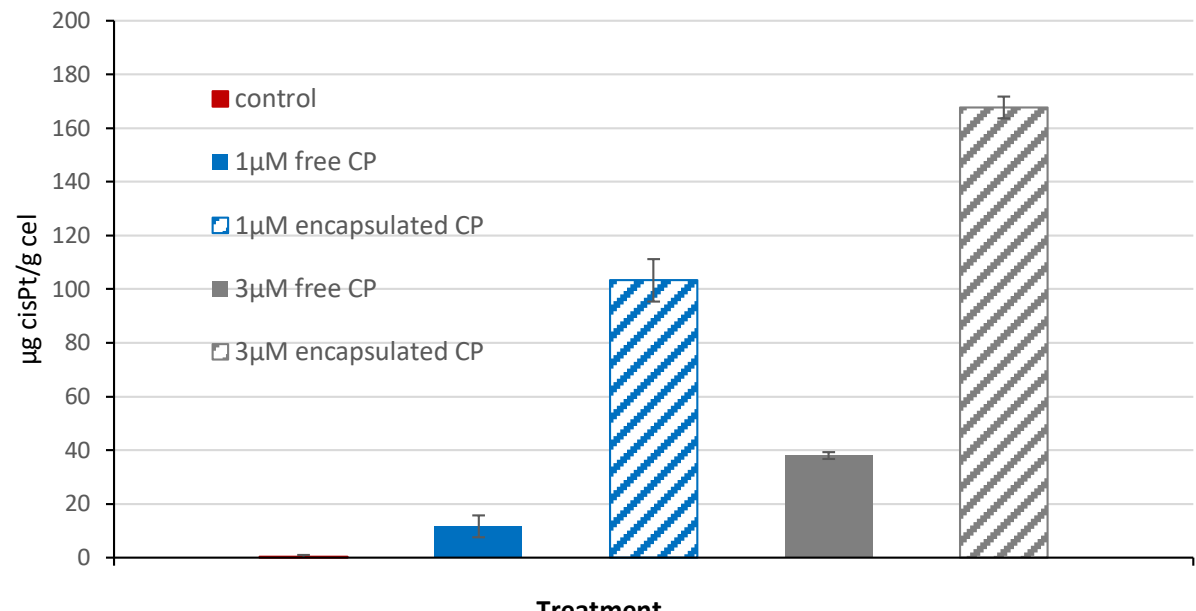

B)

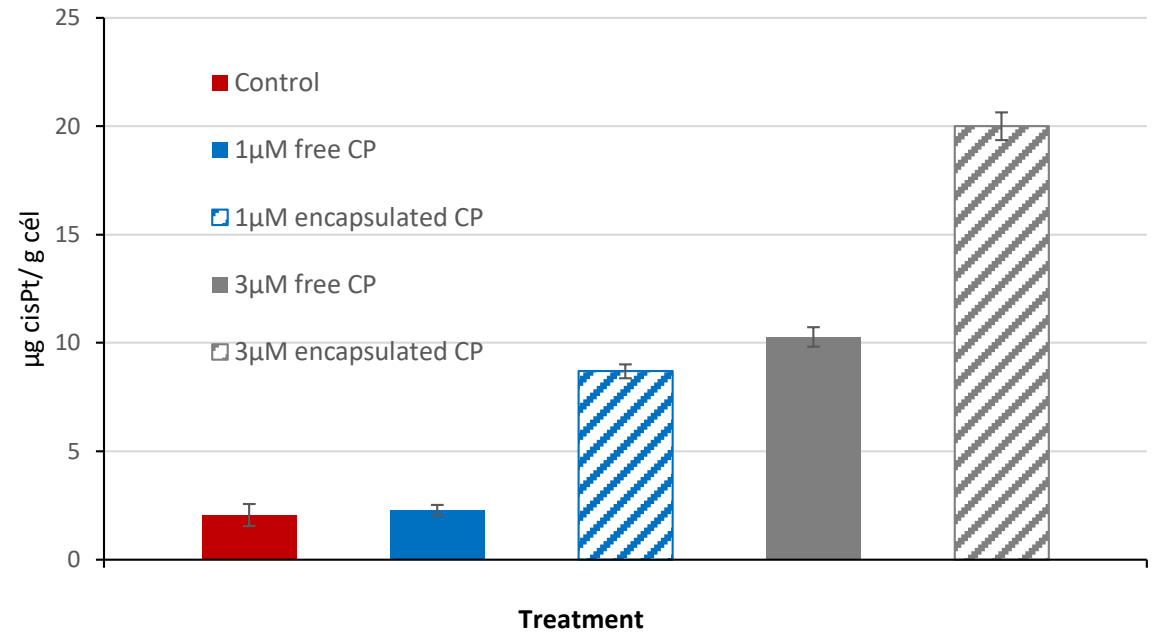

Figure 4 


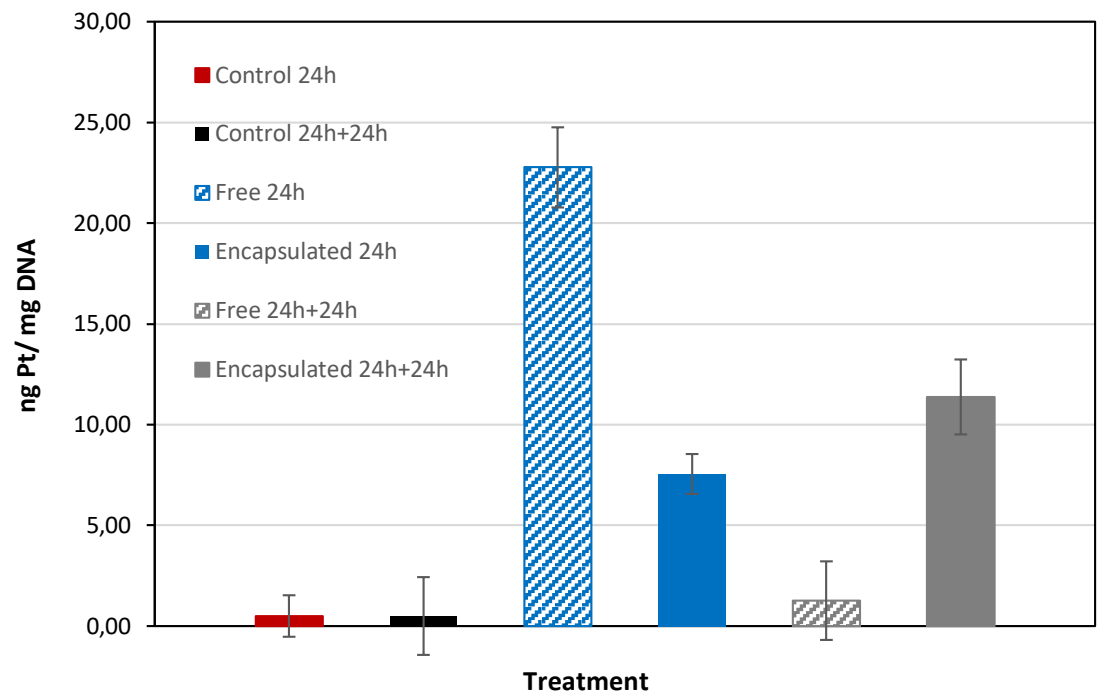

Figure 5 
A)

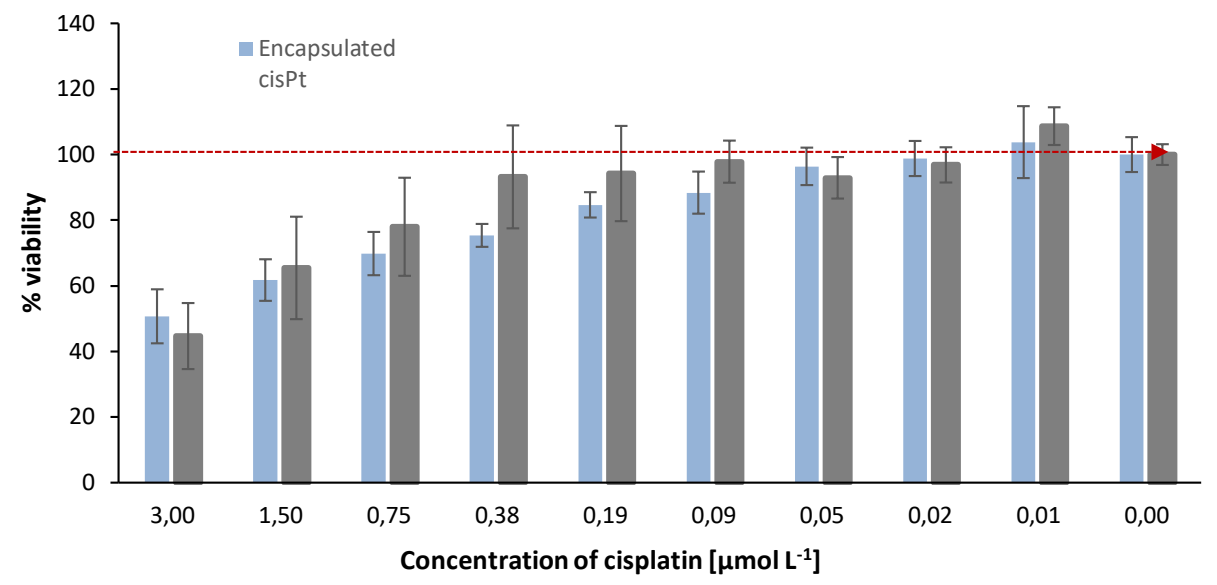

B)

$$
24 h+24 h
$$

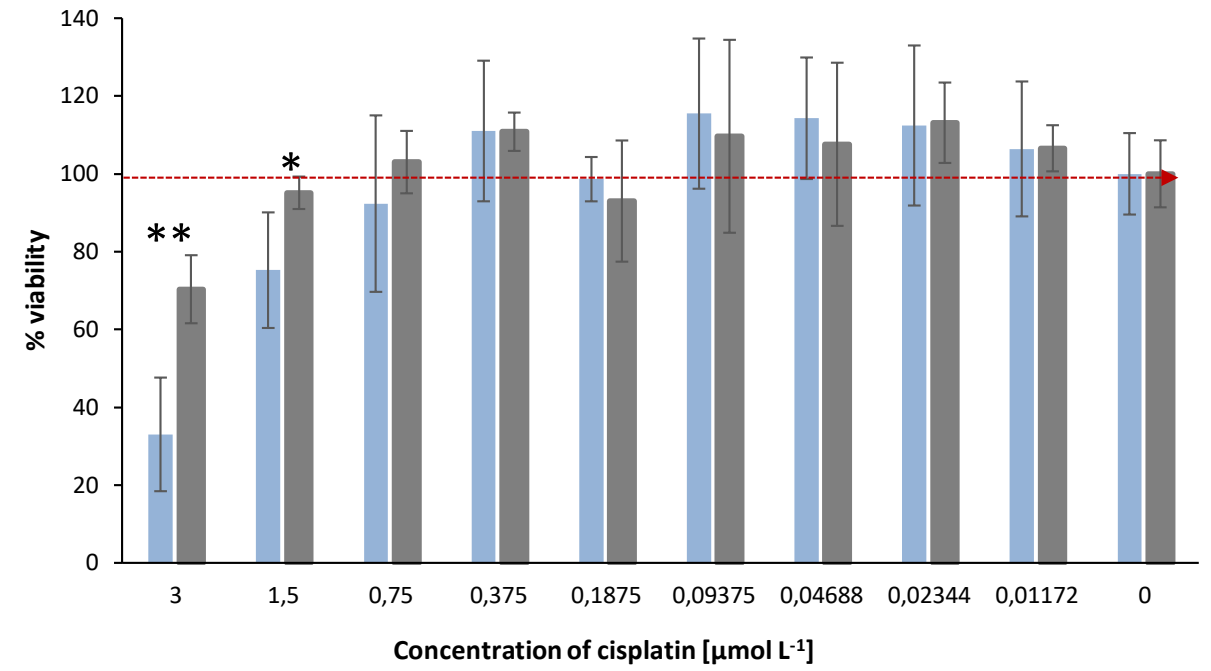

Figure 6 